Case Reports in
Gastroenterology
Case Rep Gastroenterol 2020;14:415-419

DOI: 10.1159/000508425

Published online: August 14, 2020

(c) 2020 The Author(s)

Published by S. Karger AG, Basel

www.karger.com/crg

This article is licensed under the Creative Commons Attribution-NonCommercial 4.0 International License (CC BY-NC) (http://www.karger.com/Services/OpenAccessLicense).

Usage and distribution for commercial purposes requires written permission.

\title{
An Unexpected Cause of Recurrent Jaundice after Resolution of Acute Hepatitis E
}

\author{
Annabelle Verbeeck ${ }^{a} \quad$ Ann De Becker ${ }^{b} \quad$ Hendrik Reynaert ${ }^{a}$ \\ aDepartment of Gastro-Enterology, Universital hospital UZ Brussel, Jette, Belgium; \\ ${ }^{b}$ Department of Hematology, Universital hospital UZ Brussel, Jette, Belgium
}

\section{Keywords}

Myeloid sarcoma · Gallbladder and bile ducts · Myeloid leukemia · Hepatitis E virus

\begin{abstract}
In this report, we describe a rare case of liver enzyme disturbance caused by myeloid sarcoma of the gallbladder and biliary tract. A 63-year-old man with progressive chronic myeloid leukemia presented with acute hepatitis. Viral serology revealed an infection with hepatitis $E$ virus. The liver enzymes and bilirubin improved gradually under treatment with ribavirin, but there was a flair up shortly after. Imaging including CT and echo-endoscopy showed a thickened infiltrated gallbladder wall and dilated bile ducts, suspected for myeloid sarcoma. Biopsy of an atypical skin lesion, present at the same time, confirmed the diagnosis of acute extramedullary leukemia. After induction chemotherapy, hematological improvement was seen together with a decrease of bilirubin and liver enzymes and a normalization of the bile ducts and gallbladder on imaging. However, three months later, myeloid leukemia progressed again, and the patient deceased.

\section{Case Report}

A 63-year-old male patient was diagnosed with atypical chronic myeloid leukemia (BCRABL negative, JAK2 V617F positive). Because of rapid progression of the leukemia, he was 


\section{Case Reports in Gastroenterology}

Case Rep Gastroenterol 2020;14:415-419 DOI: $10.1159 / 000508425$

Verbeeck et al.: Myeloid Sarcoma of the Biliary Tract

treated with induction chemotherapy: idarubicine $12 \mathrm{mg} / \mathrm{m}^{2} \mathrm{~d} 1-3$ and cytarabine $200 \mathrm{mg} / \mathrm{m}^{2}$ $\mathrm{d} 1-7$, followed by consolidation chemotherapy with cytarabine $1,500 \mathrm{mg} / \mathrm{m}^{2} / 12 \mathrm{~h}$ on days 1 , 3 , and 5 . However, only a few weeks later, the patient relapsed. Since a JAK2 V617F mutation was present, targeted treatment with ruxolitinib was initiated. In the meantime, a donor search was initiated to be able to proceed to allogeneic stem cell transplantation once adequate disease control was reached.

Four months later, the patient developed an asymptomatic rise in liver enzymes. Blood tests showed alanine aminotransaminase 1,637 U/L (reference 21-72 U/L), aspartate aminotransaminase $993 \mathrm{U} / \mathrm{L}$ (reference 17-59 U/L), gamma-glutamyl transferase $416 \mathrm{U} / \mathrm{L}$ (reference $<73 \mathrm{U} / \mathrm{L}$ ), alkaline phosphatase $270 \mathrm{U} / \mathrm{L}$ (reference 38-126 U/L), and total bilirubin $10.5 \mathrm{mg} / \mathrm{dL}$ (reference $0.2-1.3 \mathrm{mg} / \mathrm{dL}$ ). Abdominal ultrasonography revealed normal radiographic features of liver, gallbladder, and bile ducts. The histopathologic examination of a liver biopsy confirmed acute severe panlobular hepatitis. Viral screening proved an acute hepatitis E infection: positive hepatitis E virus (HEV) IgM with HEV RNA 1.44E+03 [1]. Screening for other viral and autoimmune causes was negative. There was no spontaneous clearance of HEV after 3 months. Therefore, the patient was treated with ribavirin $200 \mathrm{mg} 3 \times /$ day, resulting in a substantial improvement of the liver enzymes and bilirubin; and after three months, he achieved a complete HEV viral load clearance.

However, towards the end of the treatment with ribavirin, he was re-admitted to the hospital because of progressive jaundice and mild abdominal pain in the right upper quadrant. Peripheral blood tests showed a rise in bilirubin $(10.8 \mathrm{mg} / \mathrm{dL})$ and liver enzymes: elevated gamma-glutamyl transferase 1,076 U/L, alkaline phosphatase $336 \mathrm{U} / \mathrm{L}$, alanine aminotransaminase $144 \mathrm{U} / \mathrm{L}$, and aspartate aminotransaminase $79 \mathrm{U} / \mathrm{L}$. Abdominal ultrasonography and CT scan revealed for the first time dilated intra- and extrahepatic bile ducts and a thickened gallbladder wall in the absence of gallbladder stones (Fig. 1). Cholecystitis was initially suspected, but the patient had no fever, no biochemical signs of systemic inflammation, and there was no effect of empiric antibiotic treatment. Endoscopic ultrasonography confirmed a thickened wall of the gallbladder (Fig. 2a) and a dilatated common bile duct (Fig. 2b) without stones, but rather an infiltrated wall of the gallbladder and the common bile duct, suggestive for tissue infiltration by a malignancy. A spy glass cholangioscopy with biopsy or echo-endoscopy with fine needle aspiration was not performed because of significant thrombocytopenia with important bleeding risk. Simultaneously, a few atypical skin lesions on the patient's chest were observed, which allowed a safer access for biopsy.

The histological examination of this skin tissue revealed the presence of a high amount of blast cells, consistent with the diagnosis of leukemia cutis signaling relapse of the leukemia with extramedullary disease. Bone marrow aspirate and biopsy confirmed disease progression to acute myeloid leukemia (AML) despite an initial favorable response to ruxolitinib. Therefore, the patient was switched to salvage chemotherapy with fludarabine, cytarabine, idarubicine, and G-CSF (FLAG-Ida). The bilirubin level and cholestatic liver enzymes decreased gradually after blast reduction with chemotherapy, and the wall thickness of the gallbladder as well as the common bile duct dilatation returned to normal. All taken together, this presentation was highly suggestive for extramedullary leukemic infiltration into the bile ducts and gallbladder, also called myeloid sarcoma (MS). Despite his initial response, only three months later, disease progression was noticed again. The patient deceased shortly thereafter. 


\section{Case Reports in Gastroenterology}

Case Rep Gastroenterol 2020;14:415-419

DOI: $10.1159 / 000508425$

(c) 2020 The Author(s). Published by S. Karger AG, Basel www.karger.com/crg

Verbeeck et al.: Myeloid Sarcoma of the Biliary Tract

\section{Discussion}

This case is unique, given the two episodes of liver enzyme disturbance shortly after each one another but with very different causes. The first rise in liver enzymes in our patient was caused by an infection with HEV, which should always be suspected in immunocompromised patients. The source of the second liver test disturbance was far less clear. After excluding a broad range of other possible diagnoses, we found out that it was induced by an extremely rare presentation of MS in the biliary tract. Thus, with this case, we would like to remind researchers to keep a broad perspective in mind, certainly in immunodepressed patients, and certainly when the results are conflicting.

HEV genotype 3 and 4 are endemic in most high-income countries. Transmission is mainly zoonotic, with pigs as the primary host. In addition, HEV can be transmitted through transfusion with infected blood and blood products [1-4]. It is likely that our patient was infected with HEV via this way, since he received multiple blood transfusions during a period of 8 weeks before the virus was detected. During this time, the patient claimed not to have eaten raw pig meat, wild boar, or shellfish. Immunocompromised individuals often fail to clear the virus spontaneously and are at risk to develop chronic hepatitis $\mathrm{E}$ with possible progression to liver fibrosis and eventually cirrhosis [1]. In solid organ-transplant patients, EASL, the European Association for the Study of the Liver, recommends decreasing immunosuppression at diagnosis of chronic HEV infection, which can yet lead to spontaneous viral clearance. However, if HEV replication persists three months after the detection of HEV RNA, ribavirin monotherapy at a median dose of $600 \mathrm{mg} /$ day can be tried for 12 weeks.

Guidelines for the treatment of HEV in non-solid organ-transplant immunocompromised patients, like patients with hematological disorders or in stem-cell-transplant recipients, are less clear. A few case reports and small series suggest that ribavirin, PEGylated-interferon- $\alpha$, or the combination of both was effective for treating HEV infection in these patients $[1,5,6]$. Thus, given the absence of spontaneous viral clearance after 3 months in our patient, the impossibility to reduce immunosuppressive therapy, and the need for a bone marrow transplantation in the near future, we decided to treat our patient with ribavirin. This treatment was successful, since no viral load of HEV RNA was detectable in the serum after three months of therapy.

The recurrent rise in bilirubin and liver enzymes together with a dilatation of the bile ducts and acalculous gallbladder wall thickening was caused by an extramedullary presentation of AML in the biliary structure, called MS. The HEV viral load had already been cleared by this time, and hepatitis had disappeared. Other causes of acalculous cholecystitis were also excluded: There were no signs of sepsis, trauma, or pancreatitis, nor was the patient critically ill at that time. Renal, liver, and heart failure can provoke gallbladder wall thickening, but they do not generate bile duct dilatation. Nor were there signs of primary or secondary sclerosing cholangitis, IgG4 disease, or other (auto-immune) diseases. Hence, given the prior, the biliary imaging mentioned above, and the appearance of leukemic infiltration in the skin at the same time, the diagnosis of MS in the gallbladder and bile ducts was highly probable. Disappearance of the lesions after chemotherapy confirmed our diagnosis.

MS is a solid tumor consisting of blasts and myeloid progenitors that mainly occurs in patients suffering from AML, with a reported incidence of $2.5-9 \%$ in all patients with AML. It can also be found in patients with other myeloproliferative disorders such as essential thrombocytosis and polycythemia [6]. MS may occur as a presenting sign or during the course of the myeloproliferative disorder. Less frequently, it precedes leukemia by months or years or is even revealed without evidence of a myeloproliferative disease [7]. It usually develops in the 


\section{Case Reports in Gastroenterology}

\begin{tabular}{l|l}
\hline Case Rep Gastroenterol 2020;14:415-419 \\
\hline DOI: 10.1159/000508425 & $\begin{array}{l}\text { ○ 2020 The Author(s). Published by S. Karger AG, Basel } \\
\text { www.karger.com/crg }\end{array}$ \\
\hline
\end{tabular}

Verbeeck et al.: Myeloid Sarcoma of the Biliary Tract

bones, skin, or lymph nodes. Presentation in the gastrointestinal tract, in particular in the biliary tract, is extremely rare, demonstrated by the lack of studies on this matter [7-10]. Nevertheless, given the clinical importance, MS should be excluded in case of an obstructive jaundice in a patient with a history of leukemia. Wall thickening of the gallbladder and bile duct with low contrast enhancement on imaging and the absence of gallstones contribute to the suspicion [11].

Treatment with systemic chemotherapy to achieve complete remission of MS followed by allogeneic hematopoietic stem cell transplantation is likely to achieve the best results as it is the case for AML [12-14]. Chevallier et al. [13] assessed the outcome of 51 patients with MS who underwent allogeneic hematopoietic stem cell transplantation (alloHSCT) in a retrospective multicenter study. They concluded that alloHSCT performed early in the course of MS is a valid therapeutic option and that remission status at the time of alloHSCT was associated with improved overall survival [13]. Despite this, the prognosis of MS remains poor. Randomized controlled clinical trials are required to improve clinical practice, but given the low incidence, it is difficult to perform studies specifically designed for MS. Therefore, current practice is to follow similar therapeutic strategies as described in AML treatment.

In the current literature, we did not find a correlation between viral infection, like HEV, and the development or progression of MS.

\section{Statement of Ethics}

The subject gave his informed consent to publish this case.

\section{Conflict of Interest Statement}

The authors have no conflict of interest.

\section{Funding Sources}

There was no funding.

\section{Author Contributions}

Annabelle Verbeeck wrote the case report. Hendrik Reynaert and Ann De Becker both checked and corrected the paper if necessary.

\section{References}

1 European Association for the Study of the Liver. EASL clinical practice guidelines on hepatitis E virus infection. J Hepatol. 2018 Jun;68(6):1256-71.

2 Hewitt PE, Ijaz S, Brailsford SR, Brett R, Dicks S, Haywood B, et al. Hepatitis E virus in blood components: a prevalence and transmission study in southeast England. Lancet. 2014 Nov;384(9956):1766-73.

3 Zaaijer HL. No artifact, hepatitis E is emerging. Hepatology. 2015 Aug;62(2):654.

4 Satake M, Matsubayashi K, Hoshi Y, Taira R, Furui Y, Kokudo N, et al. Unique clinical courses of transfusiontransmitted hepatitis E in patients with immunosuppression. Transfusion. 2017 Feb;57(2):280-8. 


\section{Case Reports in Gastroenterology}

\begin{tabular}{l|l}
\hline Case Rep Gastroenterol 2020;14:415-419 \\
\hline DOI: 10.1159/000508425 & $\begin{array}{l}\text { @ 2020 The Author(s). Published by S. Karger AG, Basel } \\
\text { www.karger.com/crg }\end{array}$ \\
\hline
\end{tabular}

Verbeeck et al.: Myeloid Sarcoma of the Biliary Tract

5 Alric L, Bonnet D, Beynes-Rauzy O, Izopet J, Kamar N. Definitive clearance of a chronic hepatitis E virus infection with ribavirin treatment. Am J Gastroenterol. 2011 Aug;106(8):1562-3.

6 Tavitian S, Peron JM, Huguet F, Kamar N, Abravanel F, Beyne-Rauzy O, et al. Ribavirin for chronic hepatitis prevention among patients with hematologic malignancies. Emerg Infect Dis. 2015 Aug;21(8):1466-9.

7 Bartley AN, Nelson CL, Nelson DH, Fuchs DA. Disseminated extramedullary myeloid tumor of the gallbladder without involvement of the bone marrow. Am J Hematol. 2007 Jan;82(1):65-8.

8 Lee JY, Lee WS, Jung MK, Jeon SW, Cho CM, Tak WY, et al. Acute myeloid leukemia presenting as obstructive jaundice caused by granulocytic sarcoma. Gut Liver. 2007 Dec;1(2):182-5.

9 Holzwanger E, Alam Z, Hsu E, Hsu A, Mangano M, Kathman D. A case of granulocytic sarcoma or extramedullary acute myelomonocytic leukemia of the gallbladder. Am J Case Rep. 2018 Oct;19:1262-6.

10 Ojima H, Hasegawa T, Matsuno Y, Sakamoto M. Extramedullary myeloid tumour (EMMT) of the gallbladder. J Clin Pathol. 2005 Feb;58(2):211-3.

11 Choi EK, Byun JH, Lee SJ, Jung SE, Park MS, Park SH, et al. Imaging findings of leukemic involvement of the pancreaticobiliary system in adults. AJR Am J Roentgenol. 2007 Jun;188(6):1589-95.

$12 \mathrm{Yu} \mathrm{T}, \mathrm{Xu} \mathrm{G}, \mathrm{Xu} \mathrm{X}$, Yang J, Ding L. Myeloid sarcoma derived from the gastrointestinal tract: A case report and review of the literature. Oncol Lett. 2016 Jun;11(6):4155-9.

13 Chevallier P, Mohty M, Lioure B, Michel G, Contentin N, Deconinck E, et al. Allogeneic hematopoietic stemcell transplantation for myeloid sarcoma: a retrospective study from the SFGM-TC. J Clin Oncol. 2008 Oct;26(30):4940-3.

14 Yagi T, Ishikawa J, Takahashi M, Yamashita Y, Kusakabe S, Yoshinami T, et al. Successful treatment of duodenal myeloid sarcoma with allogeneic bone marrow transplantation and additional radiotherapy. Intern Med. 2012;51(7):769-72.

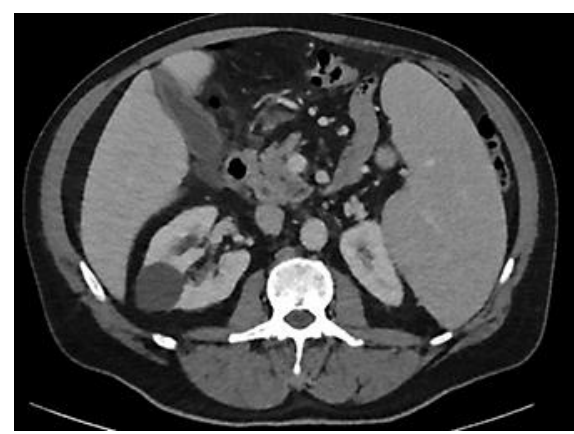

Fig. 1. CT displays a low density around the gallbladder without the presence of cholecystolithiasis. There is no dilatation of the bile ducts nor an obstructive mass.
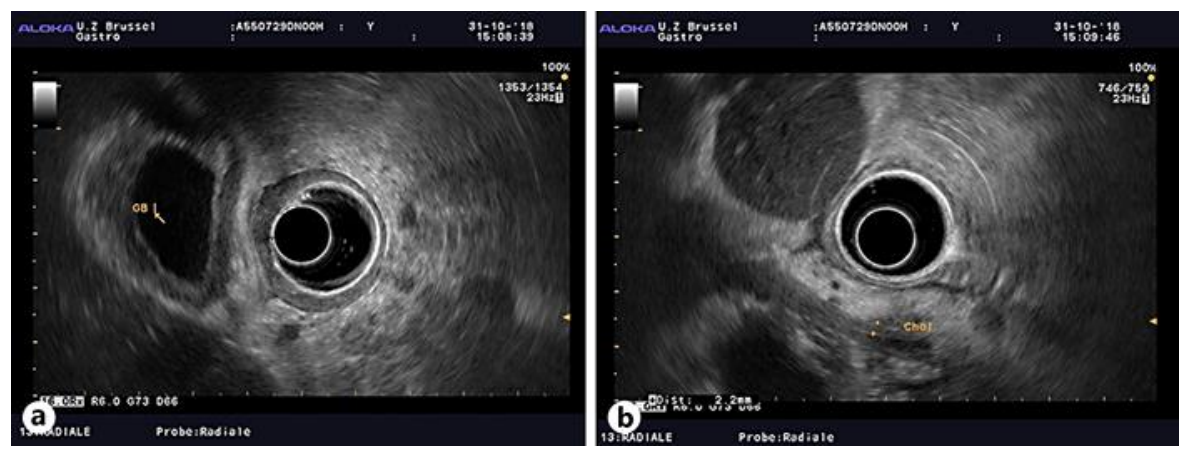

Fig. 2. Echo-endoscopy showing an infiltrative wall of the gallbladder (a) and common bile duct (b). 